\title{
Effectiveness of an educational intervention to improve nurses' knowledge on pediatric nasogastric intubation
}

\author{
Gloria Guerrero Márquez, Nurse, ${ }^{a}$ Ana Martínez Serrano, Nurse, ${ }^{b}$ \\ Montserrat Gutiérrez Juárez, Nurse, ${ }^{c}$ Ascensión García Lozano, Nurse, ${ }^{d}$ \\ Blanca Mayordomo Casado, Nurse, ${ }_{,}^{e}$ M. ${ }^{a}$ Inmaculada Torrijos Rodríguez, Nurse ${ }^{f}$ \\ Cristina Verges Pernía, Nurse, ${ }^{8}$ Esther Fernández Morales, Nurse, ${ }^{g}$ \\ Patricia Sánchez, Nurse, ${ }^{h}$ Alicia Medina Durán, Nurse, ${ }^{i}$ and \\ M. Concepción Míguez Navarro, PhD, M.D.j
}

a. Hospital Gregorio Marañón, Instituto de Investigación Sanitaria Gregorio Marañón (IiSGM), Madrid.

b. Hospital Universitario La Paz, Madrid.

c. Hospital Sant Joan de Déu, Barcelona.

d. Hospital Son Espases, Palma de Mallorca.

e. Hospital Clínico San Carlos, Madrid

f. Hospital Universitario Marqués de Valdecilla, Santander.

g. Hospital Universitario de Getafe, Madrid.

h. Hospital El Bierzo, León.

i. Hospital Infantil Universitario Niño Jesús, Madrid.

j. Hospital Gregorio Marañón, Madrid. Spain.

E-mail address: Guerrero Márquez,

Nurse: g.guerrero13@ gmail.com

\section{Funding:}

This study was internally funded by the Instituto de Investigación Sanitaria Gregorio Marañón (IiSGM).

Conflict of interest:

None.

Received: 12-4-2017

Accepted: 6-5-2018

\section{ABSTRACT}

Objective. To establish the effectiveness of an educational intervention to improve nurses' knowledge on pediatric nasogastric intubation. Methods. Multicenter, quasi-experimental, pre- and post-test study using a theoretical educational intervention based on bibliographic evidence and assessment of its effectiveness after 4 months.

Results. Delivered questionnaires: 1019. Valid questionnaires: $557(54.66 \%)$ pre-test and 246 $(24.14 \%)$ post-test. Pre- and post-test answers indicated that the implied risk always entailed by the procedure had been perceived by $53.2 \%$ and then increased to $70.7 \%(p<0.001)$. Nasogastric (NG) tube size was chosen using tables by $4.3 \%$ of participants, and increased to $24.6 \%(p<0.001)$. The length of NG tube to be inserted as measured by the nose-ear-midumbilicus distance (NEMU) method increased from $34.2 \%$ to $81.3 \%(p<0.001)$. Confirmation of NG tube placement prior to use increased from $73.1 \%$ to $86.5 \%(p<0.001)$. Confirmation of the five rights (patient, drug, dosage, route, and timing) prior to NG tube use increased from $85.6 \%$ to $91 \%$. In relation to confirmation methods, the perception that auscultation was unsafe improved from $11.7 \%$ to $31.1 \%$ $(p<0.001)$, and its use reduced from $95.1 \%$ to $81.6 \%$. The perception that the measurement of gastric $\mathrm{pH}$ was safe increased from $71.3 \%$ to $91.1 \%(p<0.001)$, and its use rose from $7.6 \%$ to $54.3 \%(p<0.001)$.

Conclusions. The educational intervention was effective to increase nurses' knowledge on pediatric nasogastric intubation.

Key words: nasogastrictubes, pediatrics, knowledge, nursing.

http: / / dx.doi.org/10.5546/ aap.2018.eng.402

To cite: Guerrero Márquez G, Martínez Serrano A, Gutiérrez Juárez M, García Lozano A, et al. Effectiveness of an educational intervention to improve nurses' knowledge on pediatric nasogastric intubation. Arch Argent Pediatr 2018;116(6):402-408.

\section{INTRODUCTION}

Nasogastric intubation is a procedure that consists in inserting a catheter or nasogastric (NG) tube through the nostril or mouth into the stomach.

It is indicated for multiple reasons. ${ }^{1,2}$ It has been estimated that approximately $10 \%$ of hospitalized patients require nasogastric intubation at some point during their stay, and, in this group, children are noteworthy. ${ }^{3}$

This procedure always implies risks, ${ }^{4-7}$ which may be compared to those entailed by any patient with a central venous catheter. ${ }^{5}$ In pediatrics, it is estimated that the incidence of complications ranges from $39 \%$ to $55 \%{ }^{3}$

An incorrect NG tube placement or its displacement after insertion are the most common causes of complications, especially if it occurs in the lungs. ${ }^{4}$

To minimize the risk, it is critical to follow the most recent, evidencebased recommendations for pediatric nasogastric intubation. This includes the following:

- Choosing the tube caliber using specific tables based on the patient's age and the procedure's purpose. ${ }^{1,8}$

- Determining the length of NG tube to be inserted using the nose-earmid-umbilicus distance (NEMU) method and/or the distance estimated by means of formulas based on the patient's height and age. The traditional method known as the measurement of the noseear-xiphoid process distance (NEX) has been associated with incorrect placement and should not be used., 
- Confirming location: prior to use, if intermittent; at least once per shift when feeding is continuous; and always after any event that may have caused tube displacement. . $^{4,6,10}$

- Among the methods to confirm NG tube placement, an abdomen X-ray is considered the gold standard, ${ }^{4,9,11-13}$ but it presents drawbacks. ${ }^{14}$ Other methods include NG tube measurement from the entry point, auscultation of air insufflated, observation of gastric aspirates, observation of respiratory symptoms, measurement of gastric $\mathrm{pH}$, and capnography/ capnometry. ${ }^{15,16}$ None of these methods is sufficiently reliable as a single method, ${ }^{3,4}$ so a combination of several methods is recommended. $4,8,9,97$

Evidence-based practices improve safety and clinical outcomes, reduce health care costs, and decrease the variation in patient outcomes, ${ }^{18}$ but this requires continuing professional development.

For this reasons, this study was proposed with the objective of analyzing the effectiveness of an educational intervention, based on bibliographic recommendations, to increase knowledge among nurses on how to insert and confirm the placement of an NG tube in pediatric patients.

\section{MATERIAL AND METHODS}

A multicenter, quasi-experimental, pre- and post-test intervention study was done using a specially designed, anonymous questionnaire on the knowledge of different aspects of everyday nasogastric intubation practice among nurses before and after a theoretical learning session.

\section{Study population and location}

The study was carried out in eight Spanish hospitals: seven tertiary care facilities and one secondary care center (Table 1).

Inclusion criteria were nurses who had worked in pediatric units for at least six months and who agreed to participate and signed the informed consent. Questionnaires were excluded if less than $75 \%$ of the questions were completed or if the experience field was left empty.

Data were collected between November 2014 and January 2015.

\section{Description of the intervention}

The intervention was carried out in 7 stages:

- Stage 1: Review of scientific bibliography on nasogastric intubation.

- Stage 2: Development of a dossier covering all the aspects to be addressed during the session. It was available at the units following the intervention for reference in case of doubts.

- Stage 3: Development of a specially designed pretest and post-test questionnaire.

- Stage 4: Training of the staff in charge of the learning session.

To prevent information transmission biases among the different hospitals, a 50-minute video was made to explain the theoretical content that had to be transmitted. The video was available on a virtual platform and was active during the entire training period (available at http:/ / youtu.be/SD6FeChUXro).

- Stage 5: Invitation of nurses from participating facilities through the heads of department. Different times and days were offered to facilitate the presence of as many nurses as possible without affecting health care activities. Participation was voluntary.

- Stage 6: Delivery and completion of the preintervention questionnaire and provision of a theoretical learning session with audiovisual material support. The session lasted approximately 60 minutes in total.

- Stage 7: Delivery and completion of the post-test questionnaire 4 months after the intervention.

\section{Questionnaire structure}

There was no previous questionnaire available to assess nurses' overall knowledge on the nasogastric intubation procedure in children, so one was developed based on the study's objectives.

To this end, we contacted a group of nurses with experience in the nasogastric intubation technique and a questionnaire including all related nursing aspects was developed. The questionnaire was pilot-tested in 15 nurses who performed this procedure and care services

TABLE 1. Facilities participating in the study and their location

\begin{tabular}{lc}
\hline Hospital & City \\
\hline Hospital Universitario Gregorio Marañón & Madrid \\
Hospital Universitario Sant Joan de Déu & Barcelona \\
Hospital Universitario Son Espases & Mallorca \\
Hospital Clínico Universitario San Carlos & Madrid \\
Hospital Universitario Marqués de Valdecilla & Santander \\
Hospital El Bierzo & León \\
Hospital Universitario de Getafe & Madrid \\
Hospital Infantil Universitario Niño Jesús & Madrid \\
\hline
\end{tabular}


routinely. Based on their feedback, the final questionnaire was prepared: items were added to better assess every aspect of the procedure and questions that could lead to confusing answers were clarified. The time required to complete the final, specially designed questionnaire was approximately 15 minutes (Annex).

\section{Ethical considerations}

The study was approved by both the Ethics and the Research Committees of each participating hospital.

\section{Statistical analysis}

Collected data were analyzed using the SPSS software $\left(\right.$ PASW $^{\odot}$ Statistics 21$)$. The results of numerical outcome measures were described as mean and standard deviation, and categorical outcome measures, as frequency and percentage. The differences in mean/median values between groups were analyzed using parametric tests (Student's $t$ test and analysis of variance [ANOVA] ) or non-parametric tests (Mann-Whitney test and Kruskal-Wallis test) depending on whether or not the assumption of homogeneity of variances was verified. A $p$ value $<0.05$ was considered statistically significant.

\section{RESULTS}

In total, 1019 nurses from the eight facilities participated. Everyone who attended the learning sessions agreed to participate and completed the questionnaire. Figure 1 corresponds to the flowchart of the study. The characteristics of participants are described in Table 2.

The results from the questionnaire were as follows:

- In the pre-test, $73.3 \%$ of participants (460) referred that they frequently did NG tube care tasks in their health care practice; in the posttest, this corresponded to $74.4 \%$ (183).

- In relation to the facility's NG intubation protocol, $63 \%$ of participants (351) indicated that they knew it, $16.9 \%$ (94) that they did not know it, and $18.9 \%$ (105) answered "Does not know/Does not answer."

- In the pre-test, $53.2 \%$ (295) indicated that the procedure always implied a risk. Such perception of risk was higher among less experienced participants $(p=0.001)$. This increased to $70.7 \%$ (174) in the post-test $(p<0.001)$.

- In relation to the five rights (patient, drug, dosage, route of administration, and timing) prior to NG tube use as a route of

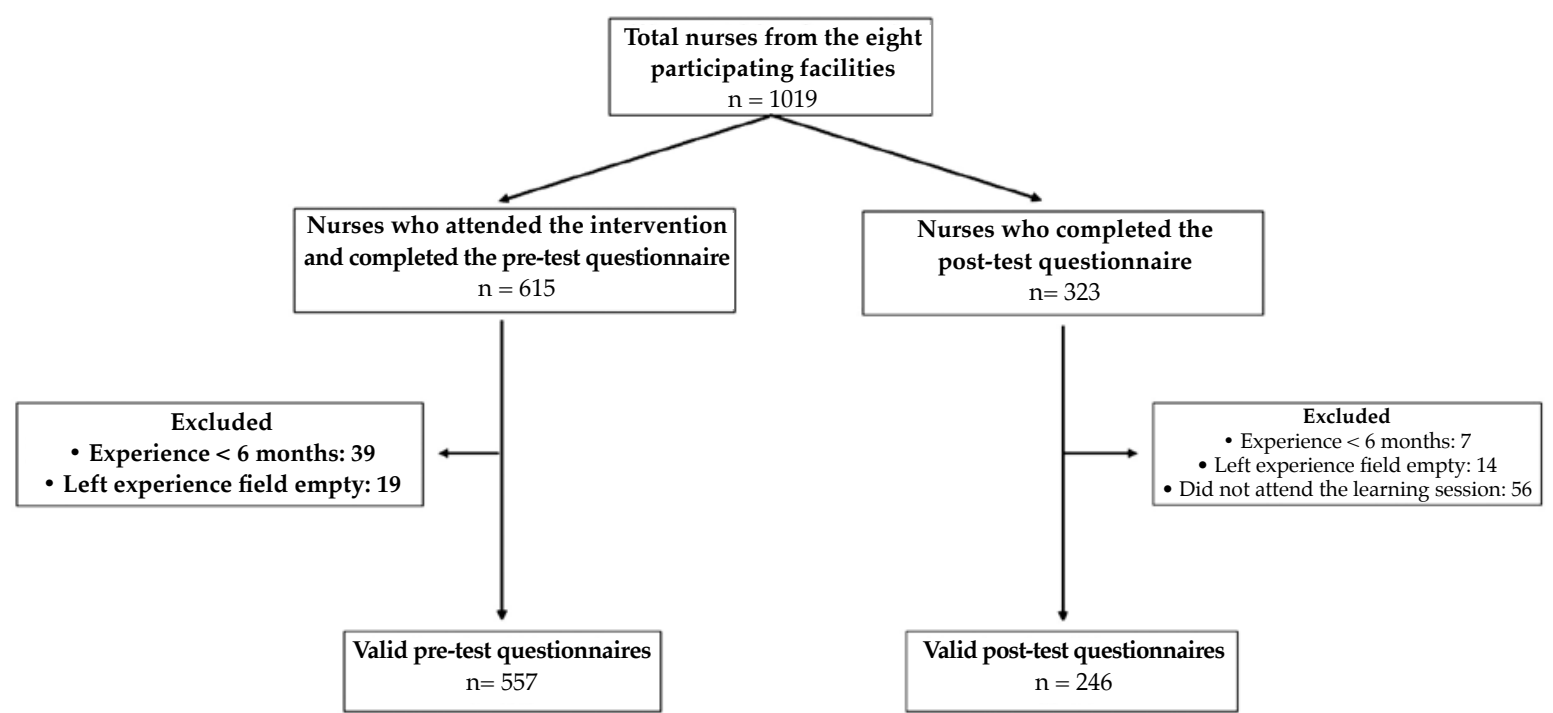

Flowchart of all nurses from the eight participating hospitals, exclusion criteria, and final pre-test and post-test questionnaires collected 
administration, in the pre-test, $85.6 \%$ (470) referred that they always reviewed them, compared to $91 \%$ (223) in the post-test; therefore, such increase was not considered statistically significant.

- The answers on the methods used to estimate NG tube caliber, length, and placement confirmation pre- and post-intervention are shown in Table 3.
- In the pre-test, $73.1 \%$ of nurses (407) indicated that they always confirmed NG tube placement before use, and this was more common among those with more experience $(p=0.005)$. After the intervention, $86.5 \%$ (212) indicated that they always confirmed it $(p=0.005)$.

- The pre- and post-intervention answers on the perception of safety provided by the different confirmation methods are shown in Table 4.

TABLE 2. Sociodemographic, work, and training characteristics of nurses participating in the study

\begin{tabular}{|c|c|c|c|}
\hline & $\begin{array}{c}\text { Pre-test } \\
\text { N }(\%)\end{array}$ & $\begin{array}{c}\text { Post-test } \\
\text { N }(\%)\end{array}$ & $\mathrm{p}^{*}$ \\
\hline \multicolumn{4}{|l|}{ Sex } \\
\hline Male & $50(9 \%)$ & $21(8.5 \%)$ & \multirow[t]{2}{*}{$\mathrm{p}=0.828$} \\
\hline Female & $505(91 \%)$ & $225(91.5 \%)$ & \\
\hline \multicolumn{4}{|l|}{ Working unit } \\
\hline Inpatient pediatric wards (>1 month old) & $255(50.1 \%)$ & $106(46.7 \%)$ & \multirow{4}{*}{$\mathrm{p}=0.03$} \\
\hline PICU and NICU & $169(33.2 \%)$ & $80(35.2 \%)$ & \\
\hline Pediatric emergency department & $54(10.6 \%)$ & $36(15.9 \%)$ & \\
\hline Neonatal ward ( $<1$ month old $)$ & $31(6.1 \%)$ & $106(46.7 \%)$ & \\
\hline \multicolumn{4}{|l|}{ Post-academic training ${ }^{* *}$} \\
\hline Master's degree & $82(14.7 \%)$ & $44(17.9 \%)$ & \\
\hline Expert & $73(13.1 \%)$ & $36(14.6 \%)$ & \multirow{5}{*}{$\mathrm{p}=0.0015$} \\
\hline Specialization in pediatrics & $29(5.2 \%)$ & $27(11 \%)$ & \\
\hline Adaptation course to the bachelor's degree & $28(5 \%)$ & $15(6.1 \%)$ & \\
\hline Doctorate & $5(0.9 \%)$ & $1(0.4 \%)$ & \\
\hline No post-graduate training & $340(61 \%)$ & $123(50 \%)$ & \\
\hline \multicolumn{4}{|l|}{ Years of experience as a pediatric nurse } \\
\hline 10 years or less & $312(56.1 \%)$ & $137(55.7 \%)$ & \multirow[t]{2}{*}{$\mathrm{p}=0.911$} \\
\hline More than 10 years & $244(43.9 \%)$ & $109(44.3 \%)$ & \\
\hline
\end{tabular}

* $\chi^{2}$ test.

** Different academic degrees recognized by Spanish universities.

PICU: pediatric intensive care unit. NICU: neonatal intensive care unit.

TABLE 3. Methods used to estimate naso/orogastric tube caliber, length, and correct placement*

\begin{tabular}{lccc}
\hline & $\begin{array}{c}\text { Pre-test } \\
\text { N (\%) }\end{array}$ & $\begin{array}{c}\text { Post-test } \\
\text { N (\%) }\end{array}$ & $\mathbf{p}^{*}$ \\
\hline Caliber estimation & & & \\
$\quad$ Professional experience & $202(36.6 \%)$ & $91(37.3 \%)$ & $\mathrm{p}=0.85$ \\
Specific tables & $24(4.3 \%)$ & $60(24.6 \%)$ & $\mathrm{p}<0.001$ \\
Observation of nostril size & $176(31.9 \%)$ & $83(34 \%)$ & $\mathrm{p}=0.55$ \\
$\quad$ Based on child's size & $339(61.4 \%)$ & $18(7.4 \%)$ & $\mathrm{p}<0.001$ \\
Estimation of the NG tube length & & & \\
NEX & $378(68.4 \%)$ & $189(34.2 \%)$ & $\mathrm{p}<0.001$ \\
NEMU & $189(34.2 \%)$ & $200(81.3 \%)$ & $\mathrm{p}<0.001$ \\
Based on the patient's height and age & $7(1.3 \%)$ & $10(4.1 \%)$ & $\mathrm{p}=0.011$ \\
Professional experience & $9(1.6 \%)$ & $2(0.8 \%)$ & $\mathrm{p}=0.362$ \\
Methods used to confirm NG tube placement & & & \\
Auscultation of air insufflated into the gastric chamber & $525(95.1 \%)$ & $20(81.6 \%)$ & $\mathrm{p}<0.001$ \\
Measurement of gastric aspirate pH & $42(7.6 \%)$ & $133(54.3 \%)$ & $\mathrm{p}<0.001$ \\
Observation of gastric aspirate characteristics & $388(70.3 \%)$ & $155(63.3 \%)$ & $\mathrm{p}=0.05$ \\
Chest X-ray & $102(18.5 \%)$ & $67(27.3 \%)$ & $\mathrm{p}=0.005$ \\
\hline
\end{tabular}

* $\chi^{2}$ test.

NG tube: nasogastric tube; NEX: measurement of the nose-ear-xiphoid process distance;

NEMU: measurement of the nose-ear-mid-umbilicus distance 
- The mean level of knowledge referred was 6.91/10 (standard deviation [DE]: 1.34) in the pre-test and 7.43/10 (SD: 1.18) in the post-test.

\section{DISCUSSION}

Few studies have been carried out on nurses' knowledge and routine practices in relation to NG tube insertion and placement confirmation in the field of pediatrics. The review of the bibliography found no studies that assessed these two aspects in an overall manner.

Results indicate that the nurses in our sample frequently do NG intubation-related tasks as part of their health care practice, which is consistent with what has been observed in other studies. ${ }^{4,15} \mathrm{In}$ spite of this, their answers evidence lack of knowledge and persistence with practices that have demonstrated to be unsafe for patients.

Before the intervention, practically half of nurses stated that they did not perceive that the procedure always implied risks, which may have led to them not taking the necessary measures to prevent errors or detect complications in an early manner. After the intervention, nurses showed a significant increase in the perception of risk. This may be the cause of the increase in the number of nurses who answered that they always confirmed NG tube placement and checked the five rights before using the NG tube as a route of administration, two aspects that are essential to detect and prevent complications in an early manner and minimize harms.

Several steps may affect patient safety during the procedure and some are related to decisions made prior to tube insertion.

The first step is choosing the adequate tube caliber. Tables are necessary to this end. ${ }^{1}$

Using other systems, as choosing the caliber based on the child's size or the nostril size increase the risk for iatrogenesis. This is especially important for taller children or those with wider alar lobules, because it leads to choosing thicker tubes. The consequences would be, on the one side, a possible damage of the nasal concha and, on the other, an increased risk for aspiration, because a larger caliber NG tube affects the lower esophageal sphincter function. ${ }^{19}$

After the learning session, the percentage of answers indicating that they used tables to choose the NG tube caliber increased significantly and the answers referring that caliber was chosen based on the child's size reduced.

The second step is determining the length of the NG tube to be inserted. Choosing an adequate length reduces the risk for incidents. ${ }^{15,16}$

When completing the questionnaires before the intervention, the nurses in our sample indicated that they mostly used the NEX method to estimate the length of the NG tube to be inserted. After the intervention, the use of the NEX method reduced and that of the NEMU method increased. The estimation using formulas also increased, although to a smaller extent, probably due to the difficulty entailed by making an accurate measurement of height, which many times is not possible given the patient's clinical status.

Lastly, and consistent with what has been described by Chan et al., ${ }^{12}$ the key step is using the adequate method to confirm NG tube placement.

Among every assessed method, and although during the learning session it was expressly stated that it was unsafe and ineffective, ${ }^{15,16}$ the auscultation of air insufflated was described as the most commonly used method before and after the intervention. The percentages observed were similar to those reported by other authors in their studies, ${ }^{12,17}$ and, as reported in those studies, participants stated that they almost always used this together with other methods. As suggested

TABLE 4. Perception of safety regarding the methods used to confirm nasogastric tube placement

\begin{tabular}{|c|c|c|c|c|c|c|c|c|c|}
\hline \multirow[t]{2}{*}{ Most commonly used methods } & \multicolumn{2}{|c|}{$\begin{array}{l}\text { Safe } \\
\text { N }(\%)\end{array}$} & \multicolumn{2}{|c|}{$\begin{array}{l}\text { Unsafe } \\
\text { N (\%) }\end{array}$} & \multicolumn{2}{|c|}{$\begin{array}{l}\text { Neither safe nor unsafe } \\
\text { N }(\%)\end{array}$} & \multicolumn{2}{|c|}{$\begin{array}{c}\text { Does not know } \\
\mathrm{N}(\%)\end{array}$} & \multirow[t]{2}{*}{$\mathbf{p}^{*}$} \\
\hline & Pre-test & Post-test & Pre-test & Post-test & Pre-test & Post-test & Pre-test & Post-test & \\
\hline $\begin{array}{l}\text { Auscultation of air insufflated } \\
\text { into the gastric chamber }\end{array}$ & $\begin{array}{c}419 \\
(77.9 \%)\end{array}$ & $\begin{array}{c}100 \\
(42 \%)\end{array}$ & $\begin{array}{c}63 \\
(11.7 \%)\end{array}$ & $\begin{array}{c}74 \\
(31.3 \%)\end{array}$ & $\begin{array}{c}55 \\
(10.2 \%)\end{array}$ & $\begin{array}{c}62 \\
(26.1 \%)\end{array}$ & $\begin{array}{c}1 \\
(0.2 \%)\end{array}$ & $\begin{array}{c}2 \\
(0.8 \%)\end{array}$ & $\mathrm{p}<0.001$ \\
\hline $\begin{array}{l}\text { Measurement of } \\
\text { gastric aspirate } \mathrm{pH}\end{array}$ & $\begin{array}{c}353 \\
(71.3 \%)\end{array}$ & $\begin{array}{c}215 \\
(91.1 \%)\end{array}$ & $\begin{array}{c}16 \\
(3.2 \%)\end{array}$ & $\begin{array}{c}6 \\
(2.5 \%)\end{array}$ & $\begin{array}{c}29 \\
(5.9 \%)\end{array}$ & $\begin{array}{c}8 \\
(3.4 \%)\end{array}$ & $\begin{array}{c}97 \\
(19.6 \%)\end{array}$ & $\begin{array}{c}7 \\
(3 \%)\end{array}$ & $\mathrm{p}<0.001$ \\
\hline $\begin{array}{l}\text { Observation of gastric } \\
\text { aspirate characteristics }\end{array}$ & $\begin{array}{c}343 \\
(67 \%)\end{array}$ & $\begin{array}{c}136 \\
(59.6 \%)\end{array}$ & $\begin{array}{c}55 \\
(10.7 \%)\end{array}$ & $\begin{array}{c}24 \\
(10.5 \%)\end{array}$ & $\begin{array}{c}106 \\
(20.7 \%)\end{array}$ & $\begin{array}{c}67 \\
(29.4 \%)\end{array}$ & $\begin{array}{c}8 \\
(1.6 \%)\end{array}$ & $\begin{array}{c}1 \\
(0.4 \%)\end{array}$ & $\mathrm{p}=0.045$ \\
\hline
\end{tabular}

${ }^{*} \chi^{2}$ test. 
by Miller et al.,$^{20}$ a reason may be that it is difficult to distance from nursing traditions, in spite of the evidence against it. However, and unlike what has been observed in a similar study by Farrington et al., ${ }^{19}$ the percentage of nurses who indicated using this method decreased slightly but significantly in the post-test questionnaire, so the intervention improved the perception of this method as unsafe.

Among the other mentioned methods, it is worth noting that answers opting for the measurement of gastric $\mathrm{pH}$ increased. This indirect method has been recommended as one of the most reliable ones as long as the $\mathrm{pH}$ is below 5, although it has limitations as well. ${ }^{5,16} \mathrm{It}$ may be conditioned by a marked increase in the perception that it is safe. It was the best rated method, even above the X-ray, which is still the gold standard for placement confirmation. ${ }^{4,5,11,12}$

In addition, nurses referred using the $\mathrm{X}$-ray confirmation more often after the intervention, although the percentage of use was still low. A cause may be that $\mathrm{X}$-rays are only frequently done in critical care units to check the patient's clinical status, so they may be used to confirm NG tube placement.

It is critical that, both during NG tube insertion and placement confirmation, nurses act in a very strict manner and in accordance with evidencebased practices because their actions may have consequences beyond those resulting from their health care practice. This may be seen in a study conducted by Northington et al., where $44 \%$ of parents of children with NG tubes at home confirmed placement by auscultation. As these investigators point out, nurses teach what they know, what they do, and what their facilities dictate. ${ }^{21}$ However, the vast field of knowledge required by nursing practice is a barrier for individual continuing professional development.

According to the bibliography, a solution to this problem is peer learning. ${ }^{21}$ Encouraging the leadership role of clinical nurses in health care units may be an alternative, which seems evident with the improved self-perception of knowledge and the apparent change in the use of the different methods observed after the intervention.

The main limitation of this study was the low rate of response to the post-test questionnaire. A potential cause may be that they were not allowed to leave their job to complete it or that they were probably not willing to be reassessed. In spite of this, the analysis of results indicates that groups were homogeneous.
Another important limitation is that actual practice was not monitored at all and that the results indicated here are exclusively based on the questionnaire answers.

It may be concluded that the educational intervention was effective to increase nurses' theoretical knowledge on pediatric nasogastric intubation because it increased the number of correct answers on practices that have been described as safe in the bibliography (use of specific tables to estimate tube caliber, the NEMU method to estimate tube length, and measurement of gastric $\mathrm{pH}$ to confirm placement) and the auscultation of air insufflated into the gastric chamber was no longer considered a safe confirmation method.

\section{REFERENCES}

1. Guerrero Márquez G. Sondaje gástrico. In Gutiérrez AJ, Guerrero Márquez G, Jiménez García R, etal. (edit). Manual de técnicas y procedimientos en urgencias de pediatría para enfermería y medicina. Madrid: Ergon; 2011:167-75.

2. Pedrón Giner C, Martínez-Costa C, Navas-López VM, et al. Documento de consenso SENPE/SEGHNP / ANECIPN / SECP sobre vías de acceso en nutrición enteral pediátrica. NutrHosp2011; 26(1):1-15.

3. Milsom SA, Sweeting JA, Sheahan H, et al. Naso-enteric Tube Placement: A Review of Methods to Confirm Tip Location, Global Applicability and Requirements. World J Surg2015; 39(9):2243-52.

4. Society of Pedatric Nurses Clinical Pactice Committee, SPN Research Committee, Longo MA. Best evidence: Nasogastric tube placement verification. J PediatrNurs2011; 26(4):373-6.

5. Irving SY, Lyman B, Northington L, et al. Nasogastric Tube Placement and Verification in Children. NutrClinPract2014; 29(3):267-76.

6. Chen YC, Wang LY, Chang YJ, et al. Potential risk of malposition of nasogastric tube using nose-ear-xiphoid measurement. PLoS One 2014; 9(2):e88046.

7. American Association of Critical Care Nurses. Initial and Ongoing Verification of Feeding Tube Placement in Adults (applies to blind insertions and placements with an electromagnetic device). Crit Care Nurse 2016; 36(2):e8-13.

8. Infants and Children Insertion and Confirmation of Placement of Nasogastric and Orogastric Tubes. Guideline [Internet]. NSW; 2016. [Accessed on: June 20 ${ }^{\text {th }}, 2017$ ]. Available at: http://www1.health.nsw.gov.au/pds / ActivePDSDocuments/GL2016_006.pdf.

9. Ellett MLC, Cohen MD, Perkins SM, et al. Comparing Methods of Determining Insertion Length for Placing Gastric Tubes in Children 1 Month to 17 Years of Age. J Spec PediatrNurs2012; 17(1):19-32.

10. Tsujimoto $H$, Tsujimoto $Y, N a k a t a Y$, et al. Ultrasonography for confirmation of gastric tube placement. Cochrane Database Syst Rev 2017; 4:CD012083.

11. Tho PC, Mordiffi S, Ang E, Chen H. Implementation of the evidence review on best practice for confirming the correct placement of nasogastric tube in patients in an acute care hospital. Int J Evid Based Healthc2011; 9(1):51-60.

12. Chan EY, Ng IHL, Tan SLH, et al. Nasogastric feeding practices: A survey using clinical scenarios. Int J Nurs Stud 2012; 49(3):310-9. 
13. Ryu JA, Choi K, Yang JH, et al. Clinical usefulness of capnographic monitoring when inserting a feeding tube in critically ill patients: retrospective cohort study. $B M C$ Anesthesiol2016; 16(1):122.

14. Guerrero-Márquez G, Martínez-Serrano A, MíguezNavarro C. Sondaje naso/orogástrico en el paciente pediátrico. Revisión de métodos de comprobación de la ubicación. Rev Rol Enferm2014; 37(9):575-80.

15. Irving SY, Lyman B, Northington L, et al. Nasogastric Tube Placement and Verification in Children: Review of the Current Literature. Crit Care Nurse 2014; 34(3):67-78.

16. Clifford P, Heimall L, Brittingham L, Finn Davis K. Following the evidence: enteral tube placement and verification in neonates and young children. J Perinat Neonatal Nurs2015; 29(2):149-61.
17. Bourgault A, Heath J, Hooper V, et al. Methods Used by Critical Care Nurses to Verify in Clinical Practice. Crit Care Nurse 2015; 35(1):e1-7.

18. Black AT, Balneaves LG, Garossino C, et al. Promoting evidence-based practice through a research training program for point-of-care clinicians. J NursAdm2015; 45(1):14-20.

19. Farrington M, Lang S, Cullen L, StewartS. Nasogastric tube placement verification in pediatric and neonatal patients. PediatrNurs2009; 35(1):17-24.

20. Miller J, Drummond Hayes D, Carey KW. ¿Práctica basada en la evidencia o vaca sagrada? Nursing (Ed Esp Internet) 2016; 33(2):34-42.

21. Northington L, Lyman B, Guenter P, etal. Current Practices in Home Management of Nasogastric Tube Placement in Pediatric Patients: A Survey of Parents and Homecare Providers. J PediatrNurs2017; 33:46-53. 
ANNEX

PRE- AND POST-TEST QUESTIONNAIRE

Please, complete the following questions on the sociodemographic characteristics that best adjust to your personal profile.

Sex: Male.

Female.

Age:

Experience as a nurse: years, months.

Experience as a pediatric nurse: years, months.

Type of employment contract:

Permanent.

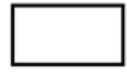

Temporary.

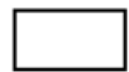

Work shift:

Morning.

Afternoon.

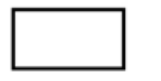

Night.

Rotating.

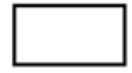

Unit where you work:

- Inpatient pediatric ward.

- PICU and NICU.

- Pediatric emergency department.

- Neonatal ward.

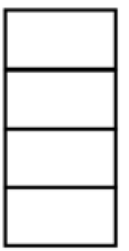

If you received post-graduate training, indicate the highest completed category:

- Doctorate.

- Master's degree.

- Pediatric Nursing Specialist.

- Expert.

- Adaptation course to the bachelor's degree.

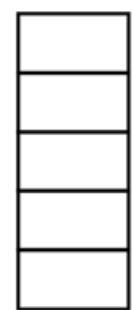


The following questions are related to the naso/orogastric tube insertion and confirmation procedure in children. To complete the questionnaire, mark with a circle or an " $\mathrm{X}$ " the answer that best describes your knowledge and routine practice.

1. Indicate how often you perform nurse care tasks in relation to the naso/orogastric tube as part of your routine practice:
a) Every day.
b) Very often.
c) Often.
d) Rarely.
e) Exceptionally.

2. Do you know the hospital's naso/orogastric intubation protocol?
a) Yes.
b) No.
c) Does not know, does not answer.

3. Do you think the nasogastric intubation procedure entails any type of implied risk for the pediatric patient's safety?
a) Always.
b) Almost always.
c) Sometimes.
d) Almost never.
e) Never.

4. If you are a nurse taking care of a patient with a naso/orogastric tube, do you routinely verify nasogastric tube placement (before giving a medication or feeding, at least once per shift during continuous enteral nutrition, and always after an event that may have caused tube displacement)?
a) Always.
b) Almost always.
C) Sometimes.
d) Almost never.
e) Never. 
5. Do you explain the naso/orogastric intubation procedure to the pediatric patient depending on his/her age and cognitive level?
a) Always.
b) Almost always.
C) Sometimes.
d) Almost never.
e) Never.

6. Do you check, before giving a medication or feeding a patient by naso/orogastric tube, that he/she is the correct patient?
a) Always.
b) Almost always.
c) Sometimes.
d) Almost never.
e) Never.

7. Do you check, before giving a medication or feeding a patient by naso/orogastric tube, that it is the correct drug or food?
a) Always.
b) Almost always.
C) Sometimes.
d) Almost never.
e) Never.

8. Do you check, before giving a medication or feeding a patient by naso/orogastric tube, that it is the correct dosage?
a) Always.
b) Almost always.
c) Sometimes.
d) Almost never.
e) Never. 
9. Do you check, before giving a medication or feeding a patient by naso/orogastric tube, that the tube is the correct route of administration?
a) Always.
b) Almost always.
C) Sometimes.
d) Almost never.
e) Never.

10. Do you check, before giving a medication or feeding a patient by naso/orogastric tube, that it is the correct timing for administration?
a) Always.
b) Almost always.
c) Sometimes.
d) Almost never.
e) Never.

11. What method do you use to estimate the naso/orogastric tube caliber (diameter) to be inserted? You may choose several options.
a) Based on my own professional experience.
b) I check specific tables considering the patient's age.
C) Based on the patient's nostril size.
d) Based on the child's size.
e) Other.

12. Do you do any calculations to estimate the length of the naso/orogastric tube to be inserted prior to insertion?
a) Always.
b) Almost always.
c) Sometimes.
d) Almost never.
e) Never. 
13. What method do you USE to estimate the length of the naso/orogastric tube to be inserted? You may choose several options.

a) Anatomical landmarks: direct distance from the point of insertion (nose or mouth) to the ear lobe and, from there, to the xiphoid process (NEX method).

b) Anatomical landmarks: direct distance from the point of insertion (nose or mouth) to the ear lobe and, from there, to the midpoint between the xiphoid process and the umbilicus (NEMU method).

c) Based on formulas for the patient's height and age.

d) Based on my own professional experience.

e) Other.

14. What methods for confirming naso/orogastric tube placement do you KNOW? You may choose several options. Mark with an "X".

\begin{tabular}{|l|l|}
\hline Auscultation of air insufflated into the gastric chamber. & \\
\hline Observation for presence of bubbling. & \\
\hline Measurement of gastric aspirate pH. & \\
\hline Observation of respiratory symptoms after insertion. & \\
\hline Observation of gastric aspirate characteristics. & \\
\hline Capnography/capnometry. & \\
\hline Chest X-ray. & \\
\hline Other (please, specify): & \\
\hline
\end{tabular}


15. What methods do you USE AS PART OF YOUR ROUTINE PRACTICE to confirm naso/orogastric tube placement? You may indicate several of the following options. Mark with an "X".

\begin{tabular}{|l|l|}
\hline Auscultation of air insufflated into the gastric chamber. & \\
\hline Observation for presence of bubbling. & \\
\hline Measurement of gastric aspirate pH. & \\
\hline Observation of respiratory symptoms after insertion. & \\
\hline Observation of gastric aspirate characteristics. & \\
\hline Capnography/capnometry. & \\
\hline Chest X-ray. & \\
\hline Other (please, specify): & \\
\hline
\end{tabular}

16. Do you make any kind of indelible mark to indicate the length of the naso/orogastric tube to be inserted?
a) Always.
b) Almost always.
c) Sometimes.
d) Almost never.
e) Never. 
16. Do you make any kind of indelible mark to indicate the length of the naso/orogastric tube to be inserted?
a) Always.
b) Almost always.
c) Sometimes.
d) Almost never.
e) Never.

17. When you have to aspirate gastric contents, if you do not manage to complete it, what would you do to facilitate aspiration? You may choose several options.
a) I use a syringe of smaller caliber.
b) I use a syringe of larger caliber.
c) I move the patient.
d) I move the nasogastric tube.
e) None.
f) Does not know/does not recall.

18. Indicate how safe you consider the following naso/orogastric tube placement confirmation methods when intubation is done "at the bedside" (1: very unsafe; 2 : unsafe; 3 : neither safe nor unsafe; 4 : safe; 5 : very safe). Mark with an "X".

\begin{tabular}{|l|l|l|l|l|l|l|}
\hline & $\mathbf{1}$ & $\mathbf{2}$ & $\mathbf{3}$ & $\mathbf{4}$ & $\mathbf{5}$ & $\begin{array}{c}\text { know how } \\
\text { to assess it. }\end{array}$ \\
\hline $\begin{array}{l}\text { Auscultation of air insufflated into the gastric } \\
\text { chamber. }\end{array}$ & & & & & & \\
\hline Observation for presence of bubbling. & & & & & & \\
\hline Measurement of pH. & & & & & & \\
\hline Observation of respiratory symptoms after insertion. & & & & & & \\
\hline Observation of gastric aspirate characteristics. & & & & & & \\
\hline Capnography/capnometry. & & & & & & \\
\hline
\end{tabular}


19. On a scale from 1 to 10 , where 1 is the worst score and 10 the best, what score would you give to your level of knowledge on pediatric naso/orogastric intubation (rounded value).

\begin{tabular}{|l|l|l|l|l|l|l|l|l|l|}
\hline 1 & 2 & 3 & 4 & 5 & 6 & 7 & 8 & 9 & 10 \\
\hline
\end{tabular}

20. Would you like to receive specific training on pediatric naso/orogastric intubation?
a) Yes.
b) No.
c) Does not know, does not answer. 